\title{
LA PERCEPCIÓN DE LA FLUIDEZ EN ESPAÑOL COMO SEGUNDA LENGUA
}

\author{
Carlos Sánchez Avendaño
}

\begin{abstract}
RESUMEN
Este artículo estudia el concepto de fluidez percibida en español como segunda lengua y trata de dilucidar cuáles factores lingüísticos del hablante y sociales del oyente conllevan mayor importancia en la determinación del grado de fluidez de un hablante no nativo.
\end{abstract}

\begin{abstract}
This article studies the concept of perceived fluency in Spanish as a second language and tries to elucidate which linguistic factors of the speaker and social factors of the listener have more importance in determining the grade of fluency of a non native speaker.
\end{abstract}

\section{Introducción}

El concepto de fluidez es una noción recurrente en los textos sobre adquisición y enseñanza/aprendizaje de segundas lenguas, en las pruebas de medición de la competencia oral de los hablantes no nativos (HNN) y en los exámenes de ubicación de niveles. Es, además, un concepto empleado comúnmente por los profesores de lenguas extranjeras para referirse a los logros o dificultades que presentan sus estudiantes en cuanto a su desempeño oral en la lengua meta. A pesar de la importancia de esta noción, no existe un acuerdo general ni totalmente preciso sobre lo que se ha de entender por fluidez o, por el contrario, a veces se formulan definiciones universales, que no toman en cuenta el comportamiento verbal esperado de un hablante en una determinada comunidad de habla ${ }^{1}$.

Por lo anterior, hablar de fluidez es entrar en un terreno movedizo y problemático. Sin embargo, no se puede negar la importancia de este concepto en la determinación de la capacidad comunicativa de los hablantes, pues resulta muy práctico a la hora de evaluar la facilidad de expresión de un HNN. Es, visto de otro modo, una especie de cajón de sastre que nos permite incluir elementos difíciles de medir, pero que no escapan a la percepción y a la intuición: la pronunciación, la entonación, la rapidez, la naturalidad, la continuidad.

Ser capaz de desenvolverse eficazmente en un segunda lengua es una habilidad ligada a factores de diversa índole, entre los cuales la percepción del oyente es fundamental. En el ámbito específico de la fluidez en español como L2, es necesario estudiar las normas de comportamiento real y las reportadas por la comunidad en cuanto a lo que debe entenderse por HNN fluido y, con esto, poder elaborar pruebas de medición que correspondan a la realidad y no a definiciones aisladas y sin sustento real o basadas en otras lenguas y comunidades. 


\subsection{Objetivo de este estudio}

El objetivo primordial de esta investigación es estudiar el concepto de fluidez en español como L2 desde la perspectiva del oyente, lo que se conoce como "fluidez percibida", y establecer cuáles factores sociales (del oyente) y lingüísticos (del hablante) conllevan mayor importancia en la percepción del grado de fluidez de un HNN. Esto implica estudiar cuáles son los aspectos que pesan más en esa determinación y verificar si esta se corresponde con las expectativas y presupuestos que se manejen sobre qué es ser fluido, tomando en cuenta el grado de interacción que se tenga con HNN. En este mismo sentido, interesa también observar si existe una correlación entre la evaluación intuitiva de los oyentes y los aspectos lingüístico-comunicativos, analizados objetivamente, del habla de los informantes.

\subsection{Estado de la cuestión}

Abundan los trabajos sobre la fluidez en la adquisición del inglés y, en menor medida, en la del francés, pero poco se ha hecho en el caso de la lengua española. Una buena parte de los estudios se centra en el análisis de los componentes lingüísticos y paralingüísticos de la fluidez, a saber: aspectos cuantificables como las pausas, las repeticiones y las autocorrecciones (Smith 1985, Ejzenberg 2000); el uso adecuado de la lengua meta en cuanto a la pronunciación, la entonación (Wennerstrom 2000), la sintaxis y el léxico; aspectos cualitativos como el uso de conectores y el tipo de construcciones (Smith 1985, Ejzenberg 2000); la organización de la conversación entre hablantes nativos (HN) y HNN (Morales 2000, Fiksdal 2000); y el peso de elementos no linguiísticos, tales como los gestos y las expresiones faciales (Bavelas 2000). Algunos estudios se han preocupado también por analizar los criterios utilizados por los jueces para evaluar la fluidez y las diferencias, en cuanto a los criterios empleados, entre los jueces que son profesores de la lengua aprendida y aquellos que no lo son (Freed 2000).

Otras investigaciones tratan de rescatar los aspectos sociales y culturales relacionados con la fluidez; por ejemplo, el estudio de las formas en que la cultura interactúa y afecta la fluidez. El punto más interesante de este tipo de investigaciones reside en llamar la atención de que poseer una competencia lingüística cercana a la de un HN no implica tener una competencia sociopragmática y cultural adecuadas (Doutrich 2000).

Por último, otras líneas de investigación de tendencia cognoscitiva se centran en las implicaciones que la noción de fluidez tiene para los estudios psicolingüísticos, en cuanto a la determinación de las limitaciones en la capacidad humana para el planeamiento del discurso (Pawley 2000, Segalowitz 2000).

\subsection{Marco teórico del estudio}

Son muchos los libros de texto que mencionan, aunque casi siempre solo de paso y en forma bastante imprecisa, el papel de la fluidez en el proceso de enseñanza/aprendizaje de segundas lenguas y su definición. A continuación se enumeran los componentes más frecuentemente citados:

a. Comunicación rápida, fácil y continua (Koponen 2000, Eisenstein 1988, Crystal 1993/1995, Riggenbach 2000). 
b. Poca incertidumbre y vacilación al hablar (Hedge 1993, Crystal 1993/1995, Riggenbach 2000, Ejzenberg 2000).

c. Buen dominio de la gramática y el vocabulario (Hedge 1993, Eisenstein 1988, Crystal 1993/1995, Riggenbach 2000).

d. Buen manejo de la entonación (Hedge 1993, Eisenstein 1988, Wennerstrom 2000).

e. $\quad$ Facilidad de transición (Smith 1985, Morales 2000, Fiksdal 2000).

f. $\quad$ Parecer natural al hablar (Lennon 2000, Fiksdal 2000, Brumfit 2000).

g. Pocas pausas y habla continua por un período largo (Fillmore 2000).

h. Coherencia: discurso denso y razonado (Fillmore 2000, Koponen 2000, Hedge 1993, Eisenstein 1988).

i. $\quad$ Capacidad de expresión en una gama amplia de contextos (Fillmore 2000, Smith 1985).

j. $\quad$ Creatividad e imaginación en el uso del lenguaje (Fillmore 2000).

k. Precisión y corrección (Eisenstein 1988, Richards 1992).

1. Discurso comprensible, fácil de seguir y sin interrupciones (Richards 1992, Ejzenberg 2000, Bavelas 2000).

También hay quienes se adhieren al concepto global de competencia comunicativa y asumen la mayoría de los factores citados como componentes de la fluidez (Smith 1985, Eisenstein 1988, Brumfit 2000).

Partiendo de estas definiciones, se trabajó con una caracterización operativa de fluidez. Con base en ella, se elaboraron las pruebas empleadas para medir la percepción de la fluidez por parte de hablantes nativos del español.

\subsection{Metodología}

Se realizaron diez entrevistas a estudiantes de español en Costa Rica de nacionalidad suiza y alemana, con el fin de conformar el corpus. En esta entrevista, se les pedía a los informantes que contaran diferentes momentos en sus vidas en los que hubieran sentido las siguientes emociones: felicidad/alegría, tristeza, enojo, miedo, culpa y vergüenza. Tres jueces expertos (profesores de español como segunda lengua (ESL) con una amplia experiencia en la enseñanza del ESL y en la aplicación de exámenes de ubicación de niveles) escogieron cinco de estas historias, cada una de las cuales debía representar una deficiencia específica en los siguientes aspectos: a) morfosintaxis, b) pronunciación, c) léxico, d) velocidad y facilidad de expresión, e) pragmática y discurso. También tuvieron que elegir una narración que no presentara ningún problema notable y otra en la que el habla del extranjero mostrara múltiples deficiencias. La misma entrevista se le hizo a un $\mathrm{HN}$ costarricense, con el objetivo de contar con un individuo control.

Se escogieron otros doce jueces (jueces evaluadores) para completar una encuesta preliminar y determinar la fluidez de los HNN seleccionados. La fluidez se calificó con base en una evaluación de quince rubros aplicada a cada una de las siete narraciones, en la que cada rubro tenía la forma de un diferencial semántico. Los doce jueces estaban distribuidos en tres grupos: el grupo 1 estaba conformado por cuatro profesores de ESL. El grupo 2 estaba constituido por cuatro personas que tienen contacto regular con HNN, pero que no son profesores. Por último, el tercer grupo estaba formado por cuatro personas que no tienen contacto regular con HNN del español. 


\section{El prototipo preliminar de hablante no nativo fluido}

En cuanto a la encuesta preliminar ${ }^{2}$, la comparación de los aspectos citados por los jueces evaluadores como componentes de la fluidez y las definiciones de los autores consultados muestran que existe una correspondencia bastante exacta entre los factores mencionados por unos y por otros. Según esta encuesta, se puede caracterizar el prototipo de HNN fluido como un hablante que domina los recursos morfosintácticos de la lengua, con un vocabulario abundante y variado y una pronunciación clara, mediante un discurso continuo, sin titubeos, que permite que la comunicación tenga lugar sin dificultad. Este hablante demuestra una buena comprensión auditiva, habla a una velocidad normal o rápida, sin una gran cantidad de pausas, pues no encuentra una gran dificultad en el planeamiento del discurso, es decir, se expresa en una forma que parece "natural" y es capaz de desenvolverse en diferentes situaciones comunicativas. Según esta misma encuesta, la fluidez se adquiere en la interacción con HN en situaciones reales, pero también se puede recurrir al proceso de enseñanza/aprendizaje para desarrollarla. Finalmente, la fluidez se relaciona con el registro oral de la lengua; por consiguiente, la habilidad para producir textos escritos no queda contemplada dentro de este prototipo y, más bien, resulta ser un elemento marginal.

\section{Cuadro 1}

\section{Correspondencias en las definiciones de fluidez}

\begin{tabular}{|c|c|}
\hline $\begin{array}{l}\text { Componentes de la fluidez según los } \\
\text { autores reseñados en el marco teórico. }\end{array}$ & $\begin{array}{l}\text { Componentes de la fluidez citados } \\
\text { por los jueces evaluadores. }\end{array}$ \\
\hline 1. Comunicación rápida, fácil y continua. & $\begin{array}{l}\text { "Se puede comunicar sin mayores dificultades." } \\
\text { "Se puede comunicar con facilidad de una manera natural y fluida. } \\
\text { No titubea al hablar ni debe detenerse para pensar la palabra o } \\
\text { conjugación verbal." } \\
\text { "Se expresa sin dificultad a la hora de la conversación". } \\
\text { "Puede comunicarse efectivamente a una velocidad normal." } \\
\text { "Habla el español en forma continua, sin pensar mucho cómo se } \\
\text { dicen las palabras." }\end{array}$ \\
\hline 2. Poca incertidumbre y vacilación. & $\begin{array}{l}\text { "No titubea al hablar ni debe detenerse para pensar la palabra } \\
\text { al hablar o conjugación verbal." } \\
\text { "Habla el español en forma continua, sin pensar mucho cómo se } \\
\text { dicen las palabras." }\end{array}$ \\
\hline $\begin{array}{l}\text { 3. Buen dominio de la gramática y } \\
\text { el vocabulario. }\end{array}$ & $\begin{array}{l}\text { "Domina las estructuras básicas y tiene bastante vocabulario." } \\
\text { "Puede expresarse claramente con corrección } \\
\text { gramatical, vocabulario abundante." } \\
\text { "Se expresa (usando bien las formas gramaticales y con } \\
\text { jugación de los verbos)" } \\
\text { No se detiene "para pensar la palabra o conjugación verbal correcta." } \\
\text { Habla "sin pensar mucho cómo se dicen las palabras." } \\
\text { "Sabe expresarse con gran variedad de vocabulario." }\end{array}$ \\
\hline 4. Parecer natural al hablar. & $\begin{array}{l}\text { "Se puede comunicar con facilidad de una manera natural." } \\
\text { "Habla en forma natural." } \\
\text { "Expresa con naturalidad todos sus pensamientos." }\end{array}$ \\
\hline $\begin{array}{l}\text { 5. Pocas pausas y habla continua por un } \\
\text { periodo largo. }\end{array}$ & $\begin{array}{l}\text { "Puede comunicarse efectivamente a una velocidad normal." } \\
\text { "Se puede comunicar con facilidad de una manera natural y fluida." }\end{array}$ \\
\hline
\end{tabular}




\begin{tabular}{|l|l|}
\hline & $\begin{array}{l}\text { "Habla el español en forma continua." } \\
\text { "Sabe expresarse con rapidez." }\end{array}$ \\
\hline 6. Capacidad de expresión en una gama & $\begin{array}{l}\text { "Se desenvuelve bien en diferentes situaciones." } \\
\text { amplia de contextos. }\end{array}$ \\
\hline 7. Precisión y corrección. & $\begin{array}{l}\text { "Puede expresarse con corrección gramatical." } \\
\text { Usa "bien las formas gramaticales." } \\
\text { "Habla un buen español." } \\
\text { "Se expresa correctamente." }\end{array}$ \\
\hline $\begin{array}{l}\text { 8. Discurso comprensible, fácil de seguir } \\
\text { y sin interrupciones. }\end{array}$ & $\begin{array}{l}\text { "Puede expresarse claramente." } \\
\text { "Puede comunicarse efectivamente." } \\
\text { "Se da a entender cuando se expresa." }\end{array}$ \\
\hline
\end{tabular}

Hay solamente tres elementos citados por los autores y que ninguno de los jueces evaluadores anotó:

1. Buen manejo de la entonación, 2. Construcción de un discurso denso y razonado y

3. Creatividad e imaginación en el uso del lenguaje

\section{Correspondencias entre la percepción de la fluidez y el habla de los HNN}

Las muestras seleccionadas por los tres jueces expertos mediante el ACFLT $^{3}$ corresponden a la siguiente descripción:

\section{Cuadro 2}

\section{HNN escogidos, con sus respectivas historias y deficiencias lingüísticas}

\begin{tabular}{|l|l|l|}
\hline Hablante no nativo & $\begin{array}{c}\text { Historia de emoción } \\
\text { evaluada }\end{array}$ & $\begin{array}{c}\text { Principal deficiencia por la } \\
\text { que fue escogido }\end{array}$ \\
\hline $\begin{array}{l}\text { HNN1: alemán, 26 años. Estudió en España dos se- } \\
\text { manas y en Costa Rica, seis semanas. Trabajó en } \\
\text { Costa Rica por seis meses. }\end{array}$ & Historia de miedo & Problemas de pronunciación \\
\hline $\begin{array}{l}\text { HNN2: suiza, 29 años. Empezó a estudiar español en } \\
\text { Suiza, pero alcanzó su nivel de desenvolvimiento en } \\
\text { Costa Rica (dos meses). }\end{array}$ & Historia de felicidad & $\begin{array}{l}\text { Problemas de léxico (transfe- } \\
\text { rencia semántica negativa) }\end{array}$ \\
\hline $\begin{array}{l}\text { HNN3: suizo, 35 años. Estudió en Cuba por dos me- } \\
\text { ses y pasó un mes en una escuela en Costa Rica. }\end{array}$ & Historia de culpa & $\begin{array}{l}\text { Deficiencias múltiples: morfo- } \\
\text { sintaxis, léxico, pronunciación } \\
\text { y discurso }\end{array}$ \\
\hline $\begin{array}{l}\text { HNN4: suizo, 24 años. Pasó casi un año en Costa Ri- } \\
\text { ca, donde estudió por tres meses. }\end{array}$ & Historia de enojo & Problemas de morfosintaxis \\
\hline $\begin{array}{l}\text { HNN5: suiza, 27 años. Estudió español en Canarias } \\
\text { por dos meses y en Costa Rica por tres meses. }\end{array}$ & Historia de miedo & $\begin{array}{l}\text { Problemas de discurso y falta de } \\
\text { interés en realizar la tarea }\end{array}$ \\
\hline $\begin{array}{l}\text { HNN6: alemán, 21 años. Estudió dos meses en Cos- } \\
\text { ta Rica. Antes solamente había tomado un curso de } \\
\text { dos semanas en Alemania. }\end{array}$ & Historia de culpa & $\begin{array}{l}\text { HNN ideal en comparación con } \\
\text { los demás }\end{array}$ \\
\hline $\begin{array}{l}\text { HNN7: alemán, 31 años. Estudió español en Alema- } \\
\text { nia, España, México y Guatemala por diez años en } \\
\text { total. En Costa Rica estudió por tres meses. }\end{array}$ & Historia de enojo & Problemas de velocidad y pausas \\
\hline
\end{tabular}


En lo concerniente a la evaluación elaborada como un diferencial semántico ${ }^{4}$, los jueces escucharon las siete narraciones y calificaron quince aspectos para cada una de ellas.

Al realizar el análisis de los resultados, se trató de encontrar las relaciones entre las evaluaciones que tenían como propósito medir la percepción de la fluidez y los hechos objetivos cuantificables e identificables (indicadores de la fluidez cognoscitiva), cuando esto fue posible. Los rubros se analizaron en tres secciones: aspectos cuantificables e identificables, para los que se podía realizar un análisis lingüístico objetivo; aspectos difíciles de cuantificar y clasificar, para los que se trató de encontrar correspondencias con otros aspectos, y aspectos globales.

\subsection{Aspectos cuantificables e identificables}

\subsubsection{Velocidad}

La polaridad en este caso se estableció entre "bastante rápida" y "muy lenta", y tenía como propósito captar la percepción de los jueces en cuanto a la continuidad temporal con la que los HNN llevaban a cabo la tarea discursiva. Se asumió que una velocidad muy lenta iba a ser indicativa de problemas en el planeamiento y producción del habla. Por el contrario, una velocidad calificada como bastante rápida sería una marca de ausencia de dichas dificultades. El análisis realizado es de tipo cuantitativo.

Interesaba medir la velocidad en términos de la tasa de habla. Se partió de que el promedio puede encontrarse entre 125 y 200 p.p.m., con un punto medio de 162 p.p.m. ${ }^{5}$. Para hacer la estimación de la tasa de habla de los HNN, se tomó una definición de palabra correspondiente a lo que Mattews (1980: 33-9) llama forma léxica o palabra fonológica, o lo que Alarcos (2000: 26) define como "unidad propia de la lengua escrita: aquello que en la escritura aparece entre blancos". Los resultados del conteo se exponen en el cuadro 3, pero debe tomarse en cuenta que los valores son relativos y sirven únicamente como cifras aproximadas para cuantificar este aspecto. También es necesario mencionar que se contaron las palabras repetidas por efecto de las vacilaciones y autocorrecciones y no se tomaron en cuenta las palabras no terminadas.

\section{Cuadro 3}

\section{Resultados del conteo de palabras}

\begin{tabular}{|c|c|c|c|c|}
\hline Hablante & $\begin{array}{c}\text { Duración total } \\
\text { de la historia }\end{array}$ & $\begin{array}{c}\text { Total de palabras } \\
\text { contabilizadas }\end{array}$ & $\begin{array}{c}\text { Cantidad de palabras } \\
\text { por minuto }\end{array}$ & $\begin{array}{c}\text { Cantidad de palabras } \\
\text { por } 30 \text { segundos }\end{array}$ \\
\hline HNN1 & 1'37' & 188 & 108 & 56 \\
\hline HNN2 & $40 ”$ & 70 & & 58 \\
\hline HNN3 & $2{ }^{\prime} 48^{\prime \prime}$ & 386 & 148 & 72 \\
\hline HNN4 & 1'43"' & 212 & 121 & 52 \\
\hline HNN5 & $26 "$ & 35 & & 35 \\
\hline HNN6 & $1 ' 10 "$ & 135 & 118 & 53 \\
\hline HNN7 & 1 , & 61 & 61 & 17 \\
\hline $\mathrm{HN}$ & 1'33" & 343 & 234 & 118 \\
\hline
\end{tabular}


Los HNN 1, 2, 4 y 6 presentan una tasa de habla por 30 segundos $^{6}$ muy parecida. El total para el HNN3 es bastante mayor (72p/30"). Las tasas de los HNN 5 y 7 son las más bajas. Al cotejar estos datos con los resultados de la evaluación (gráfico 1) ${ }^{7}$, se ve que el análisis coincide: los HNN 1, 2, 4 y 6 recibieron los puntajes más altos. Los HNN 5 y 7 obtuvieron los más bajos. La única discrepancia parece ser el HNN3, para quien se contabilizaron más palabras por minuto. Sin embargo, su habla se percibe como lenta. Por consiguiente, parece que hay otros fenómenos de por medio que dan la sensación de discontinuidad (como la discontinuidad narrativa, 3.1.8).

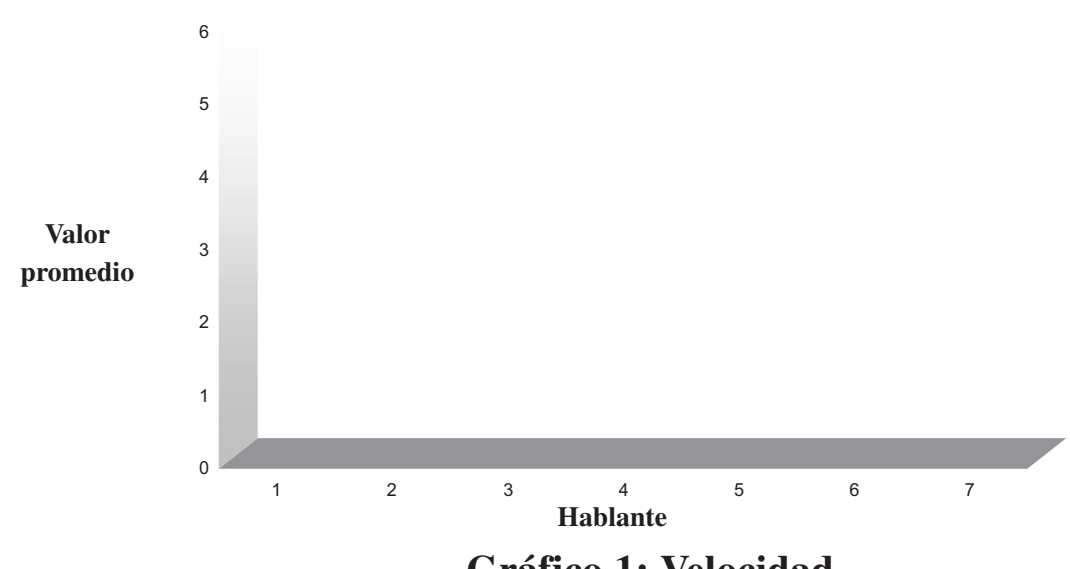

\subsubsection{Cantidad de pausas e interrupciones}

La polaridad en la calificación de este aspecto se encuentra entre "pocas" y "muchas" pausas y el tipo de análisis es cuantitativo.

Para realizar el análisis de las pausas en las historias calificadas, se tomaron en cuenta varios aspectos. Primero, el tipo de pausas: a) pausas silenciosas, b) pausas vocalizadas o llenas. Segundo, la longitud de la pausa y su clasificación aproximada en cinco grupos: de un segundo o poco menos de un segundo, 1-2 segundos, 2-3 segundos, 3-5 segundos, y de más de 5 segundos. Tercero, la posición de la pausa: antes de empezar una cláusula o dentro de esta, ante una palabra de contenido o una palabra funcional. El cuadro 4 muestra una síntesis del resultado del análisis.

\section{Cuadro 4}

\section{Cantidad de pausas contabilizadas}

\begin{tabular}{|l|c|c|c|}
\hline & Pausas vocalizadas & Pausas no vocalizadas & Total \\
\hline HNN1 & 18 & 8 & 26 \\
HNN 2 & 4 & 11 & 15 \\
HNN 3 & 10 & 39 & 49 \\
HNN 4 & 7 & 33 & 40 \\
HNN5 & 5 & 10 & 15 \\
HNN6 & 3 & 29 & 32 \\
HNN7 & 2 & 26 & 28 \\
HN & 2 & 10 & 12 \\
\hline
\end{tabular}


No existe una correspondencia exacta entre la cantidad de pausas y la evaluación hecha por los jueces evaluadores para cada hablante (gráfico 2). La HNN con el puntaje más alto resultó ser la HNN2 y, efectivamente, es la que presenta un menor número de pausas. La discrepancia se da con la HNN5, para quien también se contabilizaron quince pausas, pero ocupa el sexto lugar en la calificación. La diferencia no radica tampoco en el tipo de pausas, pues para ambas las pausas silenciosas superan a las vocalizadas. En este caso específico, nos encontramos con un fenómeno donde lo que priva es la percepción del habla en unión con otros componentes, debido a que los jueces no pudieron aislar este aspecto de los otros para calificarlo por separado. El HNN7 es el tercero con menos pausas contabilizadas (28), pero tiene el peor puntaje, muy por debajo de los demás.

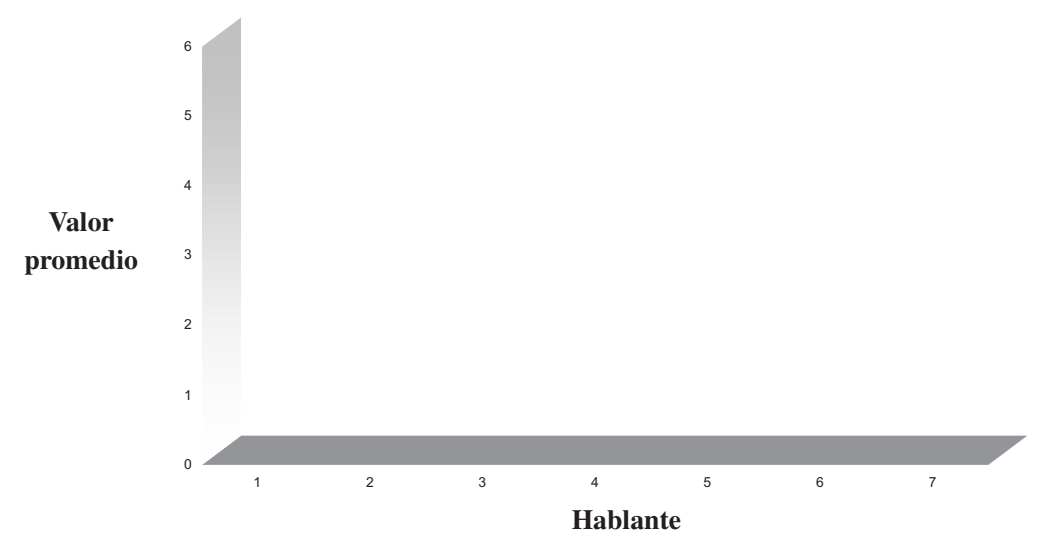

\section{Gráfico 2: Cantidad de pausas e interrupciones}

Parece, entonces, que no es la cantidad total de pausas la que motiva la calificación, sino más bien la sensación de continuidad del habla del individuo y la longitud y complejidad de su discurso. El HNN4, por ejemplo, produjo una narración muy bien desarrollada desde un punto de vista discursivo y, aunque es el segundo con más pausas contabilizadas (40), su discurso no da la sensación de ruptura que da el del HNN7.

Diversos estudios señalan que los discursos sintácticamente más complejos (y probablemente también los que lo son semánticamente) tienden a presentar más pausas silenciosas y pausas vocalizadas, posiblemente por la dificultad del planeamiento y su respectiva ejecución (Bernstein 1999: 343). No sería descabellado, por lo tanto, suponer que los hablantes están acostumbrados a tolerar, e incluso necesitar, para la decodificación del mensaje, una mayor cantidad de pausas en los discursos más complejos; pero tal tolerancia no se aplica en los casos en los que el discurso es muy simple y, en consecuencia, se esperaría una continuidad más evidente en la producción. La narración del HNN7 es muy sencilla, sintáctica y discursivamente hablando (ver 3.1.8); sin embargo, presenta muchas pausas y algunas de ellas son extremadamente largas: dos de más de cinco segundos, una incluso inmediatamente después de enunciar la primera palabra de la historia. De hecho, este hablante concentra en los primeros treinta segundos de su narración un total de once pausas (más de 20 segundos), cinco de más de tres segundos y dos de dos segundos aproximadamente. Si es cierto que la gente está más influida por cómo se dice algo que por lo que se dice, y que forma el $90 \%$ de su opinión 
sobre su interlocutor en los primeros 90 segundos (Wallwork 1997: 13), resulta bastante fácil comprender el resultado de la evaluación.

La narración de la HNN2 no es tan compleja como la del HNN4, pero sí presenta muchas menos pausas. Quizás por ello la distancia en el puntaje recibido por ambos no sea tan grande, puesto que los dos están cumpliendo con los requisitos discursivos esperables: menor número de pausas asociado a una menor complejidad sintáctica y discursiva, y mayor número de pausas ligado a una historia más compleja desde un punto de vista narrativo y sintáctico.

En el caso del HNN6, la cantidad de pausas se encuentra en el medio en relación con los demás HNN (32), pero su discurso no es sintácticamente tan simple como el de la HNN5 ni tan complejo como el del HNN4, y a ello se debe el que obtuviera el tercer lugar en el resultado total de la evaluación. Lo mismo sucede con el HNN1.

El HNN3 produjo un gran número de pausas (49), pero su historia es también la de mayor longitud. No obstante, aunque la cantidad de pausas no sea, por sí sola, el criterio que determina la evaluación (ya que está ligada a otros aspectos), tal vez la ubicación de las pausas sí coadyuve a dar la sensación de ruptura y poca continuidad en el discurso. El fragmento del HNN3 presenta 31 pausas en el interior de las cláusulas y las frases, lo que puede resultar en una sensación de interrupción de los enunciados. De hecho, también los HNN 1 y 7 muestran una cantidad considerable de pausas en posiciones internas de los enunciados (19 y 18, respectivamente) frente al número menor de pausas internas de los otros hablantes (HNN2: 11, HNN4: 16, HNN6: 15). Por su parte, el HN hizo solamente cuatro pausas en posiciones internas dentro de las cláusulas y las frases.

\subsubsection{Pronunciación}

La polaridad se estableció entre "clara" y "poco clara” y da cuenta del grado de interferencia de una pronunciación no nativa en la comprensión de los oyentes. El análisis es cuantitativo.

Se tomaron en cuenta los siguientes sonidos no nativos: la pronunciación uvular (vibrante o fricativa) de /r/ y / $/$, la no aplicación de la regla de lenización de oclusivas intervocálicas y la pronunciación del grafema «V» como [v], además de otros sonidos particulares para cada HNN. El cuadro 5 resume el análisis fonético objetivo.

\section{Cuadro 5}

\section{Sonidos no nativos}

\begin{tabular}{|c|c|c|c|}
\hline Hablante & /r/ con articulación uvular & No lenización de /b/, /d/ y /g/ & Aparición de [v] \\
\hline HNN1 & 17 & 18 & 2 \\
HNN2 & 0 & 1 & 0 \\
HNN3 & 14 & 8 & 0 \\
HNN4 & 6 & 1 & 1 \\
HNN5 & 1 & 9 & 0 \\
HNN6 & 8 & 2 & 0 \\
HNN7 & 3 & & 0 \\
\hline
\end{tabular}


La cantidad de sonidos no nativos y el tipo de estos pronunciados por los hablantes no es un factor que haya incidido directamente en la evaluación de este rubro. Parece que, para los jueces, resultaron de mayor importancia otros aspectos, y su percepción de la claridad en la pronunciación está influida por otros elementos que no necesariamente guardan relación con el componente fonético. El HNN1, escogido por los jueces expertos como representante de problemas de pronunciación, y quien, efectivamente, produjo más sonidos no nativos, no fue calificado con el puntaje más bajo en este rubro, sino que está entre los más altos (gráfico 3). En otras palabras, los jueces no calificaron la pronunciación.

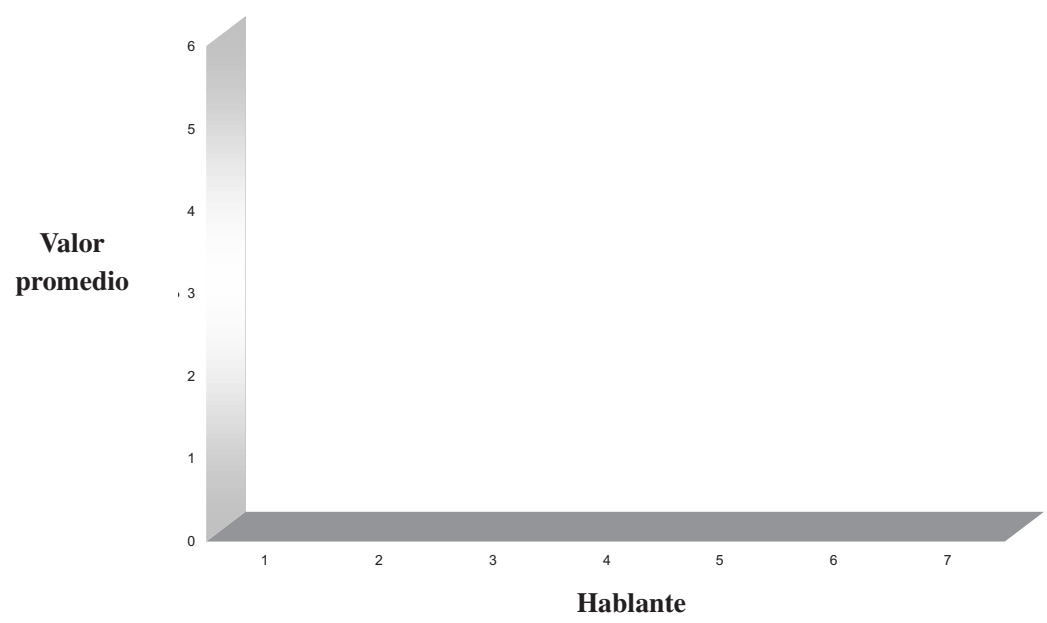

Gráfico 3: Pronunciación

\subsubsection{Entonación}

Los polos para evaluar este rubro se enunciaron de la forma "suena natural" y "no suena natural", y se plantearon con el fin de captar la percepción de los jueces evaluadores en cuanto a la proximidad de la entonación de los $\mathrm{HNN}$ a los patrones melódicos de los $\mathrm{HN}$. El análisis realizado es de tipo cualitativo: se estudiaron los ascensos y descensos en las curvas de entonación para cada hablante. Se partió de que los tonos agudos o ascensos se asocian con una mayor carga emocional, por lo que se utilizan para despertar el interés en el interlocutor. En cambio, los tonos graves o descensos se asocian con el final de los enunciados asertivos, relajan el interés y concuerdan con situaciones desapasionadas (Alarcos 2000: 51).

Al cotejar las observaciones sucintas sobre las curvas melódicas y los resultados de la evaluación, nos damos cuenta de que, en general, los HNN que hicieron un uso más variado y consecuente de estas son los que obtuvieron los mejores puntajes (HNN1: 4,66; HNN2: 5, HNN6: 4,25; HNN4: 4,08). Las calificaciones más bajas les corresponden a los HNN $5(3,41)$, 3 (3) y 7 (2,5). Los HNN 3 y 5 realizaron algunos cambios en las curvas de una manera poco adecuada o sin responder a las necesidades estilísticas de sus historias. El HNN7 echó mano de las distintas variaciones de una forma adecuada, pero su discurso se encuentra tan lleno de interrupciones (ver 3.1.1 y 3.1.2) que se percibe como poco continuo y esto, probablemente, influye también en la percepción del uso de una entonación "natural". 


\subsubsection{Uso del vocabulario}

Debido a que la muestra seleccionada como representante de problemas de léxico presenta confusión de rubros, y no una verdadera falta de estos, la polaridad se estableció entre "apropiado" e "inapropiado". El análisis es cualitativo.

Los HNN 1 y 3 son los que presentan más problemas relativos al uso de determinados rubros léxicos: confusiones y formas erróneas. En alguna medida, esto se hace patente en la evaluación de los jueces, pues ocuparon lugares bastante bajos en relación con los demás: el HNN1 quedó en cuarto lugar (5) y el HNN3, en sexto lugar $(3,75)$. Lo que es claro al comparar los problemas léxicos de ambos, es que no se trata de un asunto de cantidad, sino de tipos de errores. Si bien el HNN1 utiliza algunas formas equivocadas (p.ej. 'fijado' por 'fijo'), se comprende perfectamente en el contexto de su narración el significado del término. No pasa lo mismo con el HNN3, quien presenta muchas formas léxicas erróneas, en algunos casos casi indescifrables (como 'grupos elitos' por 'grupos élite'). Esto explicaría la diferencia en los puntajes totales.

La HNN2 es la tercera con más problemas léxicos; en su caso, son más las equivocaciones en cuanto al significado de los rubros (transferencia semántica negativa, por ejemplo 'preguntar' por 'pedir' y 'realizar' por 'darse cuenta'). Sin embargo, esto no se revela en absoluto en la evaluación, pues es ella quien precisamente obtuvo el puntaje más alto $(5,75)$.

En la historia de la HNN5 se encontraron solamente dos problemas, ambos relacionados con el mismo rubro, pero obtuvo una de las calificaciones más bajas $(4,08)$.

Los HNN 4 y 6 no presentan ningún problema y obtuvieron en la evaluación la segunda $(5,66)$ y la tercera $(5,33)$ calificaciones más altas, respectivamente.

El HNN7 comparte el puntaje más bajo $(3,75)$ con el HNN3, a pesar de no presentar ningún problema léxico.

Lo anterior apunta a que los jueces evaluadores no tomaron en cuenta solamente los problemas relacionados con el léxico en cuanto a desconocimiento de rubros, confusión, formas erróneas, etc., sino que también percibieron las diferencias en cuanto a la variedad de rubros utilizados para narrar la historia. Los HNN 5 y 7 contaron una historia muy breve y, como consecuencia, su uso de diversos rubros léxicos se percibe como limitado, pues echaron mano de pocos vocablos. Por el contrario, el HNN4 mostró una mayor variedad de palabras, al igual que el HNN6 y, como no tuvieron problemas en su manejo, fueron calificados con un puntaje alto. Los HNN 1 y 3 también demostraron poseer un conocimiento variado del vocabulario, pero tuvieron varios problemas en su uso. La única discordancia que queda es la HNN2, la más fluida en este aspecto según los jueces evaluadores, pese a sus problemas con algunos rubros (recuérdese que es la representante de problemas de vocabulario, según los jueces expertos). Tal vez se deba a que pudo acceder sin dificultad a los vocablos más relevantes para contar su historia y la confusión de ciertos términos no entorpeció la comprensión. No obstante, en el comentario general de la evaluación se trata de dar una explicación más satisfactoria a esta discrepancia.

\subsubsection{Manejo de la gramática}

La dicotomía en este aspecto se plantea entre "muchos errores" y "pocos errores", debido a que esta es la forma en la que normalmente se trata el componente morfosintáctico. 
Los errores detectados son de índole muy diversa, pero, en términos generales, los principales errores en morfosintaxis de los sujetos de este estudio se presentan en la concordancia nominal (entre el sustantivo y sus determinantes o calificativos), en las flexiones de persona de los verbos y la elección del alternante adecuado en la raíz de los verbos irregulares, y en la elección de los tiempos verbales correctos en correspondencia con el contexto.

En general, la evaluación de este aspecto coincide en forma bastante cercana con el número de errores de morfosintaxis que se pudo identificar y clasificar. La única discrepancia se halla en la calificación de la HNN5, quien, a pesar de presentar únicamente dos errores, recibió el sexto puntaje más bajo, a diferencia de otros HNN con más problemas (HNN1: 10 errores, calificación: 4,75; HNN2: 3 errores, calificación: 4,91; HNN4: 17 errores, calificación: 4,16). El HNN7 fue el que cometió más errores (22 en total) y obtuvo el puntaje más bajo $(3,25)$.

\subsubsection{Contenido de la historia}

La polaridad se estableció entre "fácil de seguir" y "difícil de seguir", por lo que el tipo de análisis responde más a la polaridad que a la etiqueta del rubro. Para determinar la "facilidad" o "dificultad" para seguir la historia, se realizó un análisis sobre la cohesión de cada narración. La cohesión se refiere a las relaciones semánticas que se dan dentro de un texto y lo definen como tal (McCabe 1999: 299). Estas relaciones se pueden hacer patentes mediante determinados marcadores formales (McCabe 1999: 300, Brown 1993: 236-273), específicamente los de referencia (pronominal, demostrativa, comparativa, sustitutiva, elíptica, conjuntiva, léxica y de progresión).

En cuanto a los resultados de la evaluación, los jueces consideraron que las dos historias más fáciles de seguir fueron las de los HNN 2 (6) y 6 (6), seguidos de cerca por el HNN $4(5,83)$. El tercer puntaje más alto lo obtuvo el HNN1 $(5,16)$. Los puntajes más bajos les correspondieron a los HNN $5(4,16), 3(3,75)$ y 7 (3).

Aunque sería esperable que la cohesión del texto facilitara el seguimiento de la historia, no es seguro que sean específicamente los marcadores de cohesión los que determinen la claridad, según se desprende del análisis. Es cierto que los HNN 2 y 6 utilizan varias estrategias a este respecto, pero también lo hacen todos los demás, con excepción de los pocos elementos presentes en la narración del HNN7 y la práctica ausencia de estos en la HNN5 (la representante de problemas discursivos, según los jueces expertos). Por otra parte, el HNN3 emplea muchos de estos mecanismos, pero recibió una calificación total bastante baja. La forma de utilizar los marcadores de cohesión por parte de los HNN no difiere de la utilización que de estos hace la HN. Si bien es cierto que hace falta tomar en cuenta otros factores discursivos que se tratan en el apartado 3.1.8., nos podemos aventurar a decir que la mayor o menor cantidad de elementos explícitos para indicar los enlaces entre las ideas del texto no necesariamente inciden en la percepción de la fluidez del discurso. Smith Sharp (1985) encontró que los marcadores de episodios (un equivalente aproximado a las partículas de progresión) y su variedad aumentan conforme aumenta el nivel de adquisición en la lengua inglesa. Solamente los HNN 1 y 4 se aproximan en cuanto a cantidad y tipos de marcadores a los empleados por la HN ('y después', 'entonces'). Los HNN 2 y 6 , por su parte, no los utilizan, pero esto no incide en su calificación. Una clave espe- 
cífica para comprender el puntaje obtenido por el HNN3 es la utilización de una referencia pronominal 'ellos' en una parte importante de la historia, sin haber hecho mención anteriormente del antecedente. En algunos estudios se plantea que esta es una característica discursiva del habla de las clases trabajadoras, que proporcionan pocas referencias y antecedentes y esperan que el oyente adivine de quién se trata y colabore en el intercambio conversacional, pero esto provoca por lo general problemas en la comunicación con personas de clase media, quienes esperan una mayor explicitud en las referencias (McCabe 1999: 299). En nuestro caso, no tiene importancia la clase social como determinante de la construcción del texto, sino el dominio de los HNN sobre las claves lingüísticas y discursivas de la comunidad que habla la lengua meta. Esta falta de especificidad puede afectar la comprensión y la cohesión de la narración.

\subsubsection{Calidad de la historia}

El énfasis en este rubro está puesto en la capacidad narrativa del hablante, por eso la polaridad se refiere a si la historia está "bien contada" o "mal contada".

Los discursos tienen formas típicas de organizar, formal y semánticamente, lo dicho. Dado que los HNN tuvieron que contar una historia personal, se trata de un género narrativo (Rintell 1990: 82, McCabe 1999: 315). Las narraciones sobre experiencias personales tienen una estructura básica, que incluye una sección de orientación (ambientación, escenografía de los acontecimientos, información de segundo plano), una evaluación (se dice cuál es la reacción del narrador ante los acontecimientos), la acción o recuento de los acontecimientos en orden cronológico, y el resultado o resolución, según la propuesta de análisis de Labov (1999). Además de esto, por tratarse de narraciones de emoción, se deben incluir en la historia los argumentos necesarios que acompañan a un determinado sentimiento para que la acción tenga sentido ${ }^{8}$.

Los HNN1 $(5,16), 2(5,75), 4(5,66)$ y $6(5,83)$ contaron narraciones bien estructuradas, con la orientación necesaria y la secuencia de acontecimientos bien organizada. El HNN3 $(3,91)$ no pudo contar la historia con suficiente claridad: la exposición de la secuencia de acontecimientos no sigue una línea evidente, la parte de orientación es muy confusa y la narración no incluye los argumentos necesarios para entender el sentimiento de culpa. El HNN7 fue el más bajo en la calificación $(3,75)$, pues su historia se quedó prácticamente en la relación de eventos de segundo plano y la secuencia en cuanto al hilo narrativo no existe, es decir, no parece haber trama.

\subsubsection{Seguridad al hablar}

Los polos de este aspecto van de "seguro" a "inseguro" al expresar el mensaje. Aunque la etiqueta parece apuntar a elementos no cuantificables o clasificables, se partió de que este es un aspecto de carácter general que engloba varios otros, que sí se pueden detectar. Basándose en la caracterización que hicieron los jueces expertos de este rubro, el habla de un individuo seguro no presenta grandes interrupciones, utiliza el circunloquio cuando desconoce un determinado rubro en lugar de pausar demasiado para tratar de recordarlo o preguntar directamente cómo se dice, y muestra firmeza en su manejo de los aspectos gramaticales y léxicos. 
En este apartado, entonces, se analizaron las reparaciones (autocorrecciones, repeticiones, reformulaciones o falsos comienzos), y las vacilaciones metalingüísticasi ${ }^{9}$, puesto que los demás elementos se trataron en los rubros anteriores. El cuadro 6 muestra los totales de reparaciones en las respectivas categorías para cada hablante (Fone=fonemas, L=palabras léxicas, $\mathrm{F}=$ palabras funcionales).

\section{Cuadro 6}

Clasificación y número de reparaciones por hablante

\begin{tabular}{|l|c|c|c|c|c|c|c|c|}
\hline \multicolumn{7}{|c|}{ Reparaciones } & $\begin{array}{c}\text { Repeticiones } \\
\text { parciales }\end{array}$ & Reformulaciones \\
\hline & Hablante & \multicolumn{2}{|c|}{ Autocorrecciones } & \multicolumn{7}{c|}{ Repeticiones } & \\
\hline & Parciales & Totales & \multicolumn{2}{|c|}{ Palabras } & Fone. & Frases & & \\
\hline HNN1 & & & L. & F. & & & & 3 \\
HNN2 & 3 & 0 & 1 & 8 & 5 & 3 & 3 & 2 \\
HNN3 & 4 & 0 & 1 & 3 & 0 & 1 & 0 & 3 \\
HNN4 & 2 & 2 & 16 & 10 & 0 & 2 & 3 & 1 \\
HNN5 & 0 & 0 & 1 & 0 & 0 & 0 & 0 & 2 \\
HNN6 & 1 & 2 & 0 & 1 & 0 & 0 & 2 & 0 \\
HNN7 & 0 & 0 & 0 & 0 & 0 & 0 & 0 & 4 \\
HN & 0 & 0 & 0 & 6 & 0 & 1 & 0 & 0 \\
\hline
\end{tabular}

Al comparar los datos objetivos con los resultados de la evaluación subjetiva, se notan algunos puntos importantes. Primero, no son la cantidad ni el tipo de reparaciones los que determinan, por sí solos, la percepción de la seguridad o inseguridad de un hablante al expresarse. Los HNN 5 y 7 son los que presentan menos reparaciones (de hecho el HNN7 no produjo ninguna), pero ocupan los últimos lugares en cuanto al puntaje recibido $(3,66$ y 1,83, respectivamente), mientras que el HNN3, en cuyo discurso la cantidad de repeticiones léxicas y de elementos funcionales, además de reformulaciones, es mayor, recibió una calificación superior a la de ambos $(3,75)$. Si observamos a los HNN con los puntajes más altos (HNN2: 5,91; HNN6: 5,5; HNN4: 5,08), se aprecia que ellos realizaron un número moderado de reparaciones, al igual que la HN. El HNN1, por su parte, ocupa un lugar intermedio en las calificaciones, pero lo cierto es que presenta más reparaciones que los tres con los puntajes más altos y también enunció varias vacilaciones metalingüísticas, elemento que los otros tres no presentan. Freed llega a las mismas conclusiones: "Aunque a menudo se ha asumido que la presencia de reparaciones en el habla no nativa (repeticiones, falsos comienzos y autocorrecciones) es indicativa de una falta de fluidez, nuestros resultados (...) sugieren que ese no es necesariamente el caso" (Freed 2000: 258).

Parece ser, entonces, que el uso de las reparaciones funciona como un elemento para dar la sensación de continuidad. El HNN7, por ejemplo, no recurre a esta estrategia en ningún momento, pero su discurso muestra una buena cantidad de rupturas y da la sensación de discontinuidad por la cantidad de pausas silenciosas que produce y la duración de estas (ver 3.1.2). Lo mismo sucede en el caso de la HNN5. Si, en lugar de dejar espacios silenciosos 
por monitorear constantemente su habla, los hablantes los llenan con una buena combinación de vocalizaciones, conectores pragmáticos y reparaciones, el flujo del discurso no se ve interrumpido y esto posiblemente tiene más importancia para los interlocutores nativos.

No obstante, una cantidad excesiva de reformulaciones y autocorrecciones puede dar también la idea de demasiados problemas en los procesos de planificación del habla y esto tiene implicaciones para la percepción de la fluidez. Los HNN 3 y 1 utilizan los recursos de las reparaciones y las vacilaciones metalingüísticas en mucha mayor cantidad que los HNN 2, 4 y 6, lo que explica las divergencias en los puntajes obtenidos. Ejzenberg (2000) afirma, a este respecto, que la competencia discursiva del hablante, es decir, su habilidad para unir y organizar su habla de una forma cohesiva y coherente, implica la integración de diversos dispositivos y estrategias, y estos son un factor fundamental en la determinación de un mayor o menor grado de fluidez: "Los hablantes más fluidos fueron mejores en proveer continuidad en su discurso y cambiar aquí y allá elementos de forma exitosa en el encadenamiento y la integración gramatical" (Ejzenberg 2000: 299). Esta autora también llama la atención sobre el hecho de que los hablantes más fluidos de su estudio tomaron la iniciativa de prevenir las rupturas en su habla en forma más constante. Los sujetos del estudio de Ejzenberg recurrieron a la redundancia y la repetición para mantener el flujo de su habla y evitar las rupturas potenciales. Por lo tanto, se puede afirmar que las reparaciones actúan como dispositivos de integración de la misma forma que lo son los conectores y los marcadores de cohesión, pero en un nivel diferente: en la formulación continua del discurso como un todo.

Como se ha visto, el aspecto que denominamos con la etiqueta "seguridad al hablar" comprende elementos de diversos tipos: pausas (tipos y duración) y uso de las reparaciones (correcciones, repeticiones, reformulaciones) como estrategia para llenar los espacios que podrían quedar vacíos en el habla mientras se planifica el discurso. Un hablante seguro sería aquel que emplea estos dispositivos en forma efectiva y evita rupturas prolongadas en su habla (HNN 1, 4 y 6); por el contrario, un hablante inseguro presenta un discurso con silencios repetidos y de larga duración (HNN 7) o abusa de las reparaciones y las vacilaciones metalingüísticas (HNN 3 y 1), lo que también tiene un resultado negativo en la percepción de su habla.

\subsection{Aspectos difíciles de cuantificar y clasificar}

Cuatro de los rubros evaluados se resisten a cualquier intento sistemático de cuantificación y clasificación. Son los aspectos que se reconocen como puramente de captación intuitiva y que se incluyeron en la prueba con el objetivo de observar la reacción de los jueces en relación con elementos poco tangibles y objetivos.

\subsubsection{Facilidad para comunicarse}

La polaridad para medir este rubro se formuló en los términos "se da a entender" y "no se da a entender". Los HNN 2 y 6 obtuvieron los puntajes más altos ( 6 cada uno) de todo el grupo. Los siguen de cerca el HNN4 $(5,91)$ y el HNN1 $(5,58)$, y en cuarto lugar tenemos a la HNN5 $(4,83)$. Los últimos lugares les corresponden a los HNN $3(4,08)$ y 7 (3,91). Según se desprende de la comparación de los resultados de este aspecto con los de los rubros objetiva- 
mente analizables, parece que la categoría que denominamos con la etiqueta "Facilidad para comunicarse" se percibe en relación con fenómenos de muy diversos tipos, tales como los relacionados con la velocidad, las pausas y la fonología (pronunciación y entonación), el léxico, la estructura discursiva, el empleo de estrategias para darle continuidad al habla y, quizás en menor medida, el empleo correcto del componente morfosintáctico.

\subsubsection{Voz de la persona}

La dicotomía se planteó entre los términos "natural" y "forzada". Este aspecto se incluyó como una forma de estudiar el comportamiento de los jueces frente a un asunto tan difícil de medir e, incluso, tan personal.

Los HNN $2(6,08), 4(5,41), 6(5,33)$ y $1(4,91)$ recibieron nuevamente los puntajes más altos. Los HNN $3(4,33), 5(3,75)$ y $7(3,41)$, por su parte, obtuvieron las calificaciones más bajas. Podría pensarse, entonces, que decir que la voz de alguien "suena natural" o "suena forzada" se correlaciona con factores tan diversos como los que condicionan la percepción de la facilidad comunicativa. Los HNN calificados más severamente en los rubros sobre "la calidad de la emisión sonora" (velocidad, pausas, entonación, pronunciación) y también en otros aspectos con una relación menos clara con la calidad de la voz (gramática, vocabulario, discurso), son quienes ostentan los puntajes más bajos en este aspecto. En conclusión, parece que si un hablante no hace las pausas únicamente en las posiciones y momentos adecuados, no realiza los cambios melódicos oportunamente y con propósitos estilísticos y su habla presenta muchos cortes, da la sensación de que su voz no suena "natural", sino más bien "forzada".

\subsubsection{Forma de contar la historia}

El énfasis se puso, en este caso, en la habilidad del narrador para atrapar al oyente en su historia, y por eso los términos para evaluarla son "interesante" y "aburrida".

Los HNN con las calificaciones más altas son, en orden decreciente, los HNN $2(5,66)$, $4(5), 6(4,25)$ y 1 (4). Los HNN con los puntajes más bajos son: $5(3,41), 3(3,33)$ y $7(1,91)$.

Sería de esperar que los rubros sobre el manejo del discurso tengan una prominencia mayor en la percepción de este aspecto. Efectivamente, se puede encontrar una correlación entre las calificaciones de los aspectos discursivos, entonativos y de seguridad al hablar y este rubro: presentación clara y ordenada de las secuencias que conforman el hilo narrativo (3.1.8), incorporación dentro del relato de los detalles necesarios para completar los argumentos que determinan un sentimiento específico (3.1.8), marcación del final de las ideas y mantenimiento del interés por lo que sigue a continuación por medio de los cambios en la entonación (3.1.4) y el manejo adecuado de las pausas (3.1.2) y las reparaciones (3.1.9). Todo esto confluye para dar la sensación de que el narrador cuenta una historia interesante. Empero, también parecen intervenir otros aspectos mucho menos tangibles y más personales.

\subsubsection{Forma de expresarse}

Este rubro se refiere a la actitud del narrador al contar su historia y se estableció en los términos "le pone ganas" y "no le pone ganas", que se corresponden con "muy entusiasta" y 
"poco entusiasta". Se refiere, principalmente, al interés en llevar a cabo la tarea con éxito.

La HNN2 es la más entusiasta al contar su historia (6), la siguen los HNN $3(5,16), 1$ $(5,08)$ y $4(5)$. Los HNN $5(4,25), 6(4,08)$ y $7(3,25)$ son los menos entusiastas. Contrario a lo que sucedió en los demás aspectos, el HNN6 recibió en este caso el segundo puntaje más bajo, y el HNN3, el segundo más alto, lo que indica que los jueces evaluadores percibieron que el HNN3 "le puso ganas" a la tarea de narrar, mientras que el HNN6 no lo hizo. De hecho, percibieron que el HNN3 fue más entusiasta que los HNN 1 y 4. El HNN7 obtuvo la calificación total más baja, nuevamente. En su caso particular, quizás la discontinuidad tan evidente de su discurso crea la impresión de "falta de interés" y monotonía.

En cuanto a las posibles correlaciones con otros rubros, se podría afirmar que influyen el manejo de la entonación, la cantidad de pausas y la calidad de la historia, al menos para los HNN 1, $2,4,5$ y 7.

\subsection{Aspectos globales}

\subsubsection{Nivel de español}

Según la evaluación, el hablante con el nivel más alto es el HNN6 $(5,66)$. El tercer puntaje más alto le corresponde al HNN4 (5,5), seguido por el HNN1 (5,25). Los hablantes con el nivel más bajo son, en orden decreciente: HNN3 $(3,91)$, HNN5 $(3,83)$ y HNN7 $(3,33)$. Es decir, en cuanto a la percepción global de la competencia de los HNN en español, la evaluación sigue reflejando los puntajes obtenidos en los otros aspectos. Los cuatro hablantes con los puntajes más altos son los mismos (HNN1, HNN2, HNN4, HNN6), al igual que los que obtuvieron los más bajos (HNN3, HNN5 y HNN7). En este caso, no es la HNN2 $(5,5)$ la que se considera como la que ha alcanzado el nivel más alto en el manejo de la lengua, sino el HNN6, pero la diferencia entre ambos es muy pequeña.

Por consiguiente, se podría afirmar que es el conjunto de todos los aspectos tratados el que incide en la percepción del nivel de dominio del español.

\subsubsection{Fluidez global}

Los HNN que, según las calificaciones totales, podemos considerar fluidos son, en orden decreciente: HNN4 (5,08), HNN2 (5), HNN6 (4,83) y HNN1 $(4,75)$. Por el contrario, serían poco fluidos los HNN5 $(3,41)$, HNN3 $(3,33)$ y HNN7 (2).

\section{La percepción de la fluidez}

Partiendo de una distinción teórica esbozada por Lennon (2000), podemos hablar de fluidez (en un sentido más cognoscitivo) y de fluidez percibida. La primera se refiere a la producción exitosa de una determinada tarea lingüística. Por su parte, la fluidez percibida enfatiza la posición del oyente y se refiere a la impresión que este tiene de la forma en que el hablante realiza los procesos psicolingüísticos del planeamiento y producción del discurso, es 
decir, si estos procesos se verifican de manera fácil y sin esfuerzo.

Lo natural, según Lennon, es que los hablantes tiendan a intentar mantener la fluidez percibida, a causa de que el no hacerlo puede repercutir de dos maneras en la interacción: el oyente puede perder el interés y el hablante puede ver afectada su imagen. Esto explica la necesidad por parte del hablante de mantener la sensación de fluidez, haciendo que sus problemas de planeamiento se vean ocultados.

Los resultados de la evaluación muestran que, al parecer, la fluidez se percibe como un todo. Esto coincide con la afirmación de Riggenbach de que varias condiciones deben darse para ser fluido, pero la falta de fluidez puede surgir de una deficiencia en un aspecto específico (Wennerstrom 2000: 103).

Todos los resultados apuntan a que el HNN7 es el prototipo de HNN no fluido. Sus problemas más evidentes son de tipo cuantificable (pausas silenciosas prolongadas, tasa de habla reducida), pero también cualitativo (problemas en la formulación de su historia); sin embargo, este HNN no muestra serios problemas de pronunciación, morfosintaxis o vocabulario. A pesar de esto, los puntajes que recibió en estos últimos rubros son bajos en comparación con otros HNN que sí presentan muchos más problemas en estas áreas y que obtuvieron puntajes más altos (por ejemplo, el HNN1: problemas fonéticos, léxicos y gramaticales; y la HNN2: problemas de transferencia semántica negativa). La notoriedad de sus dificultades de continuidad del discurso resulta en una percepción negativa de los demás aspectos, incluso de los más subjetivos (como la voz, la forma de contar la historia y la forma de expresarse). De hecho, este HNN recibió el puntaje más bajo en doce de los aspectos (nivel de español, fluidez global, velocidad, cantidad de pausas, entonación, facilidad para comunicarse, seguridad al hablar, uso del vocabulario (aspecto en el que no hay ningún problema real visible), voz de la persona, contenido de la historia, calidad de la historia, forma de contar la historia, y forma de expresarse). Este HNN, por lo tanto, fracasa en captar la atención de sus oyentes y en proyectar una imagen de fluidez.

Los HNN 3 y 5 son los que, por lo general, recibieron los puntajes más bajos, después del HNN7. El caso del HNN3 es diferente al anterior. Su fluidez es un tipo de fluidez falsa. La fluidez falsa es una estrategia para mantener un nivel alto de continuidad temporal a todo costo. La producción del habla es exitosa en términos temporales (velocidad, pausas), pero conceptual, comunicativa, formal y funcionalmente es pobre (Lennon 2000: 28). El HNN3 mantiene una tasa de habla rápida y estable; presenta muchas pausas, pero su discurso es el más largo de todos y únicamente en un fragmento las pausas cortan la línea articulatoria; emplea las reparaciones como una estrategia para llenar los silencios a toda costa, aunque esto repercuta en la claridad del mensaje, pues su narración está llena de reformulaciones y repeticiones. Sin embargo, comete una gran cantidad de errores morfosintácticos (problemas formales), muchos de los rubros léxicos que emplea no son claros (problemas formales y conceptuales) y su historia carece de un hilo narrativo claro, un conflicto reconocible y un resultado (problemas comunicativos y conceptuales). Esto afecta, por lo tanto, la percepción que se tiene de otros aspectos, como por ejemplo la velocidad (obtuvo el cuarto puntaje, por debajo de otros HNN con una tasa de habla menor como los HNN 1, 2, 4 y 6), la pronunciación (el puntaje más bajo, muy por debajo del HNN1) y en la forma de contar la historia (captación del interés del oyente). Nuevamente, la percepción de algunos aspectos, en este caso los cuantificables, se ve afectada de forma negativa por las deficiencias en determinadas áreas. Esto 
comprueba que el concepto de fluidez que manejan las personas no se refiere solamente a asuntos como continuidad temporal del habla, sino también de claridad e inteligibilidad del mensaje. Lennon afirma que ha encontrado pruebas de que los juicios de profesores experimentados y hablantes nativos de la lengua meta están influidos por factores poco tangibles y escurridizos. En otras palabras, aunque el análisis cuantitativo puede servir para medir las diferencias entre los hablantes, la percepción del oyente no está determinada únicamente por aspectos temporales (Lennon 2000: 26).

La HNN5 no tiene problemas morfosintácticos, léxicos, temporales (pausas, discontinuidades) ni fonológicos notables; no obstante, es la tercera menos fluida de acuerdo con el rubro de fluidez global. Este mismo comportamiento se observa a lo largo de la evaluación de los diferentes aspectos (velocidad, pausas, entonación, pronunciación, seguridad, vocabulario, gramática, voz, contenido de la historia, calidad de la historia, forma de contar y forma de expresarse). Su historia no presenta los problemas de la del HNN3, pero es corta (dura solamente 26 segundos) y no parece tener mucho contenido; la línea de acontecimientos es breve y no llega a captar el interés. Es la simplicidad discursiva la que influye en la percepción negativa de los demás aspectos. Si partimos de que, en términos generales, el buen desempeño de una tarea cualquiera no se percibe como complejo, sino como natural (Koponen 2000: 13), comprendemos por qué el habla de esta HNN da la impresión de poca naturalidad por ser demasiado simple. Se pone en duda su competencia no solo lingüística sino también profesional y personal, con base en la simplicidad (noción muy diferente de facilidad) con que cuenta su relato.

Si se toma a los HNN con los puntajes más altos, se puede entender mejor cómo se percibe la fluidez. La HNN2 es quien obtuvo los puntajes más altos (primer o segundo lugar) en casi todos los rubros (nivel, fluidez global, velocidad, cantidad de pausas, entonación, facilidad para comunicarse, seguridad, vocabulario, voz, contenido de la historia, calidad, forma de contar y forma de expresarse). Efectivamente, no presenta problemas de pronunciación, de pausas o de velocidad, pero sí de vocabulario. Su historia no es compleja, pero presenta todas las partes del género narrativo y logra captar la atención desde el primer momento. Esta HNN, además, logra provocar un sentimiento de empatía con la mayoría de los jueces, lo que causa un doble efecto: su habla influye en la percepción positiva de su personalidad y viceversa.

Lo mismo sucede con el HNN4, quien, en el rubro de fluidez global, es considerado el más fluido. Este HNN se mantiene entre el segundo y el cuarto puntaje más alto en casi todos los rubros (nivel, velocidad, pausas, entonación, pronunciación, facilidad para comunicarse, seguridad, vocabulario, voz, contenido de la historia, calidad de la historia, forma de contar y forma de expresarse). El único aspecto para el que obtuvo un puntaje bajo es el de manejo de la gramática. Sin embargo, esto no incide para que no sea considerado un HNN competente y fluido, aunque no el ideal. Los datos comprueban que, en efecto, la única deficiencia notable de este hablante se da en el manejo del componente morfosintáctico y esto lo notan los jueces. Podría deducirse, entonces, que cuando el discurso de un hablante es, en general, adecuado, preciso y bien construido, es más fácil centrar la atención en las deficiencias en un área específica y lograr así una evaluación intuitiva más justa y acorde con la realidad. No obstante, la relación entre la fluidez y los errores es complicada: "En términos de fluidez percibida, algunos errores pueden pasar desapercibidos en el flujo del discurso si la producción es rápida, lúcida y eficaz al expresar el pensamiento de una forma interesante que capte la atención del oyente" (Lennon 2000: 40). Esto explicaría por qué, a pesar de sus constantes errores gra- 
maticales, este HNN es juzgado como fluido.

La fluidez está determinada por una compleja red de aspectos. Los rubros que se incluyeron en la evaluación son, en buena medida, un reflejo de los criterios que los jueces evaluadores utilizaron. En otras palabras, muchos HNN fueron considerados como más cercanos o menos cercanos al ideal de fluidez por medio de criterios como su precisión gramatical, su vocabulario, su pronunciación, su facilidad de expresión, la velocidad con que hablan, la cantidad de pausas, la seguridad con que se comunican y el interés que ponen en la realización de la tarea. Asimismo, aparecieron criterios totalmente subjetivos y difíciles de evaluar, como la falta o el deseo de aprendizaje, la naturalidad y el sonar interesante.

El grado y tipo de interacción que se mantenga con HNN no parece resultar determinante en la evaluación, aunque sí se dejan entrever algunas diferencias. Los individuos sin contacto regular con HNN muestran una tolerancia menor hacia las deficiencias lingüísticas, pero también se preocupan más por la comprensión global del habla de los HNN. Por su parte, los sujetos con contacto regular son más condescendientes y el grupo de los profesores tiende a comportarse como el grupo de los individuos que no lo son. Sin embargo, esta observación no es categórica y varía mucho dependiendo del aspecto y el HNN juzgados. Lo que sí parece más seguro es que los profesores de ESL no muestran una habilidad de discriminación más desarrollada que los no profesores. Todos los jueces sobreevaluaron o infraevaluaron a determinados HNN en aspectos específicos, sin que se pueda notar una correlación entre el análisis objetivo de los hechos identificables en el fragmento de habla de los HNN y el puntaje asignado.

En cuanto a los factores lingüísticos que conllevan mayor importancia a la hora de determinar la fluidez de un HNN, los resultados son mucho más reveladores. Muchas veces los aspectos se perciben como un todo y múltiples deficiencias en unos rubros pueden provocar que los aspectos en los que no se hallan problemas notables se perciban como deficientes también. La continuidad en el discurso parece ser el aspecto de mayor relevancia. Aquí la continuidad debe entenderse como un fenómeno complejo compuesto por muchos elementos. En primer lugar, se trata de la continuidad en aspectos temporales: cantidad, duración y colocación de las pausas, tasa de habla (velocidad) y uso de reparaciones (repeticiones, reformulaciones) para proyectar la imagen de seguimiento de la idea. En segundo lugar, se trata de continuidad semántica y discursiva: coincidencia entre la información de orientación del relato, la secuencia de acontecimientos y el resultado, además de la presentación de un conflicto (dado el género discursivo y el tipo de narración) y de los argumentos propios de una determinada emoción. En todos estos elementos, el problema no se encuentra en la utilización o no utilización de, por ejemplo, las pausas y las reparaciones, sino en su forma de empleo.

La mayor o menor longitud del discurso implica que los oyentes exijan el cumplimiento de otros requisitos: un discurso corto se relaciona con menos pausas y vacilaciones (reparaciones, búsqueda de rubros léxicos, correcciones gramaticales); por el contrario, en un discurso de mayor longitud y con una línea de acontecimientos más compleja, se toleran más pausas, más reparaciones, más errores morfosintácticos y más vacilaciones en el uso de las palabras. Si el discurso largo no presenta una continuidad semántica (la línea de eventos no coincide con el resultado, la parte de orientación es excesivamente larga en comparación con los hechos del relato, no se presentan los argumentos asociados con una emoción específica), este se percibe como discontinuo y, como consecuencia, no fluido. Si un discurso es corto y no presenta muchas interrupciones, pero el oyente no percibe que la tarea se esté llevando a cabo 
con interés o se trata el tema en forma muy simple, este también se juzga como poco fluido.

En relación con los otros aspectos tomados en cuenta en este estudio, debe mencionarse que su uso adecuado y su variedad influyen en la percepción del oyente sobre la fluidez del HNN. Sin embargo, las deficiencias en, por ejemplo, morfosintaxis y léxico, se toleran mucho más si la continuidad expuesta anteriormente se percibe como aceptable. Si, por el contrario, la continuidad no es aceptable, se crea un juicio global desfavorable en el juez, lo que lo lleva a ser menos condescendiente con los errores e, incluso, a percibir deficiencias que en realidad no existen, como se demuestra en el análisis objetivo realizado para cada aspecto. Lo mismo pasa con la entonación y la pronunciación.

En este estudio también se incluyeron elementos subjetivos y de difícil análisis, con el fin de observar la reacción y el comportamiento de los jueces ante tales aspectos. Ningún juez se extrañó de tener que calificar un rubro tan personal y poco tangible como, por ejemplo, la voz de la persona, mediante una escala del tipo "natural-forzada". Esto deja en claro que, para los jueces, incluyendo a los profesores, la fluidez es un fenómeno que se asocia con muchos factores, algunos puramente intuitivos.

A partir de los resultados, se establece, asimismo, una relación estrecha entre la empatía y la percepción del desempeño oral de $\operatorname{los} \mathrm{HNN}^{10}$. Esta relación funciona en doble sentido: los HNN fluidos por lo general logran crear una empatía mayor, se los considera más competentes y se les atribuye un atractivo social más grande. Lo mismo pasa en la dirección opuesta: los HNN que logran crear por diversas razones (no menos subjetivas, como la percepción de la personalidad) una imagen de simpatía, reciben una valoración más positiva de su fluidez y los jueces son mucho más condescendientes siempre y cuando su uso de la L2 no sea muy deficiente o discontinuo. Lo mismo se aplica con un resultado desfavorable: los HNN poco fluidos son calificados como menos competentes y su atractivo social se pone en duda.

\section{Cuadro 7}

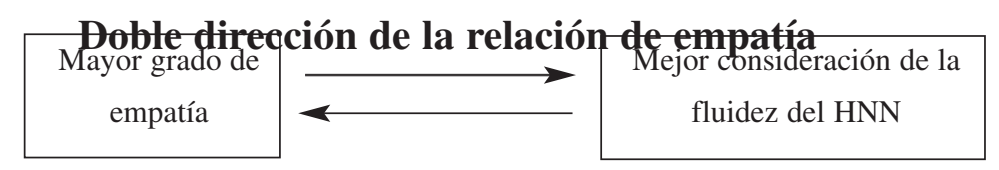

También se concluye que un HNN poco fluido no se considera apto para realizar un trabajo en que deba comunicarse regularmente con costarricenses, ni tampoco se considera una persona "interesante", digna de ocupar nuestro tiempo y paciencia, o con la que se pueda entablar una conversación sin que ello implique un verdadero esfuerzo de nuestra parte.

\section{Esquema de la formación de actitudes Guą̧rqi hacia los HNN en cuanto a su fluidez}

La fluidez de estos HNN es
baja, son inseguros, les toma
mucho tiempo hablar, no son
claros, hacen perder el interés.

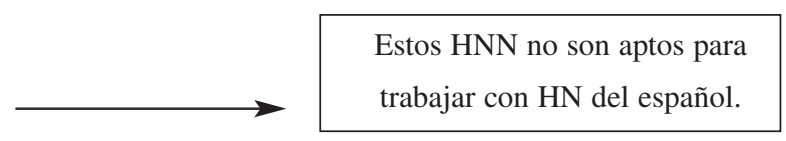




\section{Conclusiones: implicaciones pedagógicas y para la evaluación}

El concepto de fluidez percibida da cuenta de la importancia de la percepción por parte de los HN al juzgar el desempeño oral de los HNN. En esta percepción intervienen determinados factores que contribuyen a percibir, y en consecuencia a evaluar, los aspectos lingüísticos y comunicativos como negativos o positivos en relación con el discurso del HNN en su totalidad y el grado de atractivo social y la competencia que se le atribuyen.

Más que proponer una definición de fluidez objetiva y categórica, lo único que podemos hacer es elaborar prototipos relativos que resulten operativos para los propósitos específicos que nos hagamos (en términos pedagógicos y de evaluación) y tratar de que ellos reflejen de alguna manera el continuum de aceptabilidad dentro de la comunidad de habla en que trabajemos.

De acuerdo con los resultados de la percepción de la fluidez, los HN son mucho más tolerantes en relación con los errores que con la discontinuidad del discurso y esto tiene implicaciones incluso en las reacciones potenciales que reportan sobre el atractivo social y la competencia de los HNN. En lugar de incentivar en las clases de español como L2 una preocupación, e incluso a veces obsesión, por el uso totalmente correcto de la gramática, los profesores de ESL deberían promover una actitud tolerante hacia los errores y las imperfecciones que caracterizan la interlengua de los HNN, ayudarlos a asumir su proceso de aprendizaje y adquisición como tal, es decir, como un continuum compuesto por estadios, cada uno con sus particularidades, y dejar de lado la concepción de que la perfección en el manejo de una lengua es la meta principal y no la competencia comunicativa.

También habría que tomar en consideración en qué tipo de tareas vamos a aplicar el término. Concentrándonos en las destrezas orales (puesto que el prototipo de HNN fluido esbozado lo es en este sentido), la mayoría de los jueces concibe la fluidez como una habilidad que se adquiere, pero que también es susceptible de tratarse en un contexto escolar. Sin embargo, al preguntarles directamente a los profesores de ESL si creen que es una habilidad que se puede enseñar y aprender en una clase, muchos de ellos expresaron su reticencia al respecto y, más bien, afirmaron que se puede ayudar al estudiante a desarrollarla mediante actividades. En otras palabras, si no podemos enseñarles a los estudiantes a ser fluidos, al menos sí podemos facilitar el proceso de adquisición y el desarrollo de tal habilidad, y esto se logra mediante actividades que impliquen la producción oral por parte de ellos. Se trata, entonces, de recrear situaciones e involucrar a los aprendices de ESL en la producción de distintos discursos.

En cuanto a la fluidez, como se demostró en este estudio, los aspectos que conforman el mensaje no solo no se dan en forma aislada, sino que tampoco se perciben desligados unos de otros. Si por razones metodológicas debemos segmentar la lengua y enseñarla por partes, también debemos crear espacios donde se practique como un todo. La meta, entonces, será, centrar la práctica en cómo lograr determinados objetivos y valernos de los recursos de que dispongamos para tal efecto.

Los HNN que podríamos considerar dentro del umbral de fluidez cometieron errores de gramática (HNN4), emplearon algunas palabras en un sentido inapropiado (HNN2), mostraron una interferencia fonética notable (HNN1) e incluso desviaron el objetivo de contar una historia de emoción y lo suplieron con comentarios relacionados con el tema 
(HNN6), pero todos lograron finalizar la tarea con éxito. Por el contrario, los HNN que mostraron serias dificultades de continuidad, no recurrieron a estrategias para llenar los silencios (HNN7) o lo hicieron en forma excesiva a tal punto de hacer borroso el mensaje (HNN3), no contaron un relato con "pies y cabeza" (HNN3) o lo hicieron en forma muy escueta y sin interés (HNN5), quedaron por debajo del umbral de aceptabilidad en cuanto a su competencia oral en español y su fluidez. Es decir, los HNN fluidos de este estudio no lo son por hablar rápido, no hacer pausas, no cometer errores, tener una pronunciación nativa, contar historias extremadamente complejas o ser grandes oradores, sino por saber lidiar con sus respectivas deficiencias y echar mano de las estrategias y recursos de que disponían para cumplir exitosamente la tarea encomendada.

Las medidas de la corrección gramatical o fonológica no nos dicen a ciencia cierta qué tan exitoso es el comportamiento oral de un HNN. El estudio revela el problema de la calificación por escalas: se presenta una gran dispersión en la calificación de los mismos aspectos por diferentes jueces. Esto implica que la necesidad de contar con un tribunal examinador es innegable. Además, es necesario aislar el rubro respectivo para poder calificarlo, puesto que la fluidez se percibe como un todo y los problemas en un aspecto influyen negativamente en la percepción de los otros.

\section{Notas}

1. Preton (1989) afirma que se trata de etnocentrismo lingüístico el intentar extender las definiciones de fluidez de ciertas comunidades a todas las culturas.

2. La encuesta preliminar fue completada por los doce jueces evaluadores algunos días antes de llevar a cabo la evaluación de las muestras. Esta encuesta tenía como propósito captar algunas caracterizaciones intuitivas sobre lo que se entiende por fluidez y por un buen manejo del español por parte de HNN.

3. El ACTFL es una guía formulada por el Departamento de Educación de Estados Unidos para caracterizar en forma global el desempeño integrado en habla, escucha, lectura y escritura de HNN de una lengua. Los tres jueces expertos utilizaron una versión simplificada de esta guía para seleccionar el corpus.

4. Las muestras seleccionadas por los jueces expertos se colocaron al azar en una misma cinta. La exposición a los fragmentos se realizó en varias sesiones, en cada una de las cuales participó una parte de los jueces. La prueba para evaluar la fluidez fue diseñada con la forma de un diferencial semántico, en el que cada aspecto se presenta con su respectiva escala. En cada escala, se colocó de forma aleatoria el elemento más positivo o favorable a la izquierda o a la derecha, y el menos positivo o favorable al lado opuesto, esto con el fin de evitar el efecto de prueba. Los doce jueces evaluadores contaban con siete grados en cada escala para calificar quince aspectos de cada muestra.

5. Los datos sobre la tasa de habla en una conversación varían de autor en autor: 125-180 ppm (Yeni-Komshian 1999: 117), 140-180 ppm (Wingfield 1999: 247), 150-200 ppm (Oppenheim 2000: 220), 150 ppm (Bernstein 1999b: 330).

6. Se consigna el número de palabras por minuto y por medio minuto, dado que las historias de las HNN 5 y 6 son muy cortas y no alcanzan al minuto, y el hacer el conteo por 30 segundos permite poseer un promedio que sirve por igual para comparar las tasas de habla de cada uno.

7. Los resultados de la evaluación expuestos corresponden al cálculo del promedio ponderado de los punta- 
jes asignados por los jueces a cada HNN para cada rubro. En estadística, "se supone que las observaciones dentro de una clase se distribuyen uniformemente dentro de la clase y que, por ello, el punto medio las representa adecuadamente" (Gómez 1998: 287).

8. Los sentimientos se asocian con argumentos básicos, según la propuesta de Marina 1999. Por ejemplo, el argumento del sentimiento de miedo sería el siguiente: "La percepción de un peligro o la anticipación de un mal posible provoca un sentimiento desagradable, acompañado de deseos de huida" (Marina 1999: 438).

9. Acuñamos este término para dar cuenta de las emisiones del tipo “¿cómo se dice?”, “no sé”, “¡cuál es la palabra?".

10. En la última parte de la evaluación se presentaron seis preguntas con un tipo de respuesta discreta (sí/no) y su respectiva justificación. Cuatro de las preguntas tenían como objetivo captar la actitud y posibles reacciones reportadas de los jueces evaluadores frente a los HNN, según la percepción de su fluidez: "¿Contrataría usted a esta persona para un puesto en el que necesitara comunicarse constantemente con costarricenses?”, “¿hablaría con esta persona todos los días?”, “¿escucharía otras historias contadas por esta persona?”, “¿sería fácil comunicarse con esta persona?"

\section{Bibliografía}

Alarcos Llorach, Emilio. 2000. Gramática de la lengua española. Madrid: Espasa Calpe S.A.

Appel, René y Pieter Muysken. 1996. Bilingüismo y contacto de lenguas. Barcelona: Editorial Ariel.

Andersen, Elaine y otros (ed.). 1990. Developing Communicative Competence in a Second Language. Massachusetts: Heinle and Heinle Publishers.

Bavelas, Janet Beavin. 2000. “Nonverbal Aspects of Fluency”. En: Riggenbach (ed.), 91-101.

Bernstein Ratner, Nan y Jean Berko Gleason (eds.). 1999a. Psicolingüística. Madrid: McGraw-Hill/Interamericana de España.

Bernstein Ratner, Nan y Victoria A. Fromkin. 1999b. "Producción del lenguaje". En: Bernstein (ed.), 329-368.

Bonvillain, Nancy. 1993. Language, Culture and Communication. The Meaning of Messages. New Jersey: Prentice Hall.

Brown, Gullian y George Yule. 1993. Análisis del discurso. Madrid: Visor Libros.

Brumfit, Christopher. 2000. “Accuracy and Fluency: The Basic Polarity”. En: Riggenbach (ed.), 61-73.

Butterworth, Brian. 1990. “Aportaciones del estudio de las pausas en el habla”. En: Valle, Francisco et al. (eds.), 289-309. 
Crystal, David. 1995. The Cambridge Encyclopedia of Language. Cambridge: Cambridge University Press.

Crystal, David. 1993. Patología del Lenguaje. Madrid: Cátedra.

Doutrich, Dawn. 2000. “Cultural Fluency, Marginality, and the Sense of Self”. En: Riggenbach (ed.), 141-59.

Eisenstein Ebsworth, Miriam. 1988. “Accuray vs. Fluency: Which Comes First in ESL Instruction?" Internet. 12 de agosto del 2000. Disponible: http://www.eslmag.com/accuracyvsfluency.html

Ejzenberg, Roseli. 2000. "The Juggling Act of Oral Fluency: A Psycho-Sociolinguistic Metaphor". En: Riggenbach (ed.), 287-313.

Ellis, Rod. 1997. SLA Research and Language Teaching. Oxford: Oxford University Press.

Fiksdal, Susan. 2000. "Fluency as a Function of Time and Rapport. En: Riggenbach (ed.), 128-140.

Fillmore, Charles J. 2000. “On Fluency”. En: Riggenbach (ed.), 43-60.

Freed, Barbara F. 2000. "Is Fluency, Like Beauty, in the Eyes (and Ears) of the Beholder?" En: Riggenbach (ed.), 243-65.

Freed, Barbara F.(ed.). 1995. Second Language Acquisition in a Study Abroad. Philadelphia: John Benjamins Publishing.

Glisan, Elieen W. y Judith L. Shrum. 1994. Contextualized Language Instruction. Boston: Heinle and Heinle Publishers.

Gómez Barrantes, Miguel. 1998. Elementos de estadística descriptiva. San José: Editorial de la Universidad Estatal a Distancia.

Henerson, Marlene E., Lynn Lyons Morris y Carol Taylor Fitz-Gibbon. 1987. How to Measure Attitudes. Los Angeles: Center for the Study of Evaluation.

Jaworski, Adam y Nikolas Coupland. 1999. The Discourse Reader. Nueva York: Routledge.

Krashen, Stephen D. 1981. Second Language Acquisition and Second Language Learning. Oxford: Pergamon Institute of English.

Krashen, Stephen D. 1987. Principles and Practice in Second Language Acquisition. Oxford: Prentice-Hall International. 
Koponen, Matti y Heidi Riggenbach. 2000. "Overview: Varying Perspectives on Fluency". En: Riggenbach (ed.), 5-24.

Labov, William. 1999. "The transformation of experience in narrative". En: Jaworski (ed.), 221-35.

Lennon, Paul. 2000. "The Lexical Element in Spoken Second Language Fluency”. En: Riggenbach (ed.), 25-42.

Marina, José Antonio y Marisa López Penas. 1999. Diccionario de los sentimientos. Barcelona: Anagrama.

Mattews, P.H. 1980. Morfología. Introducción a la teoría de la estructura de la palabra. Madrid: Paraninfo.

McCabe, Allyssa. 1999. "Oraciones combinadas: texto y discurso". En: Bernstein (eds.), 297-328.

Morales-López, Esperanza. 2000. "Fluency Levels and the Organization of Conversation in Nonnative Spanish Speakers' Speech”. En: Riggenbach (ed.), 266-286.

Oppenheim, Nancy. 2000. "The Importance of Recurrent Sequences for Nonnative Speaker Fluency and Cognition". En: Riggenbach (ed.), 220-42.

Pawley, Andrew. 2000. “The One-Clause-at-a-Time Hypothesis”. En: Riggenbach (ed.), 16399.

Preston, Denis R. 1989. Sociolinguistics and Second Language Acquisition. Oxford: Basil Blackwell.

Richards, Jack C. 1992. The Language Teaching Matrix. Nueva York: Cambridge University Press.

Rintell, Ellen M. 1990. “That's Incredible: Stories of emotion told by second language learners and native speakers." En: Andersen, Elaine (ed.), 75-94.

Riggenbach, Heidi (ed.). 2000. Perspectives on Fluency. Michigan: The University of Michigan Press.

Sánchez Avendaño, Carlos. 2001. La percepción de la fluidez en español como segunda lengua. Tesis de maestría: Universidad de Costa Rica.

Segalowitz, Norman. 2000. “Automaticity and Attentional Skill in Fluent Performance”. En: Riggenbach (ed.), 200-19. 
Smith Sharp, Heidi. 1985. La fluidez: ¿meta estática o dinámica en la adquisición del inglés como segunda lengua? Tesis de maestría: Universidad de Costa Rica.

Umaña Aguiar, Jeanina. 1989. "La relación entre actitudes lingüísticas, conducta e identidad". Revista de Filología y Lingüística. XV (2): 121-9.

Valle, Francisco et al. (eds.). 1990. Lecturas de Psicolingüística 1: Comprensión y producción del lenguaje. Madrid: Alianza Editorial.

Wallwork, Adrian. 1997. Discussions A-Z. Advanced. Cambridge: Cambridge University Press.

Wennerstrom, Ann. 2000. “The Role of Intonation in Second Language Fluency”. En: Riggenbach (ed.), 102-27.

Wingfield, Arthur y Debra Titone. 1999. "Procesamiento de oraciones". En: Bernstein (eds.), 245-95.

Yeni-Komshian, Grace H. 1999. "Percepción del habla". En: Bernstein (eds.), 113-67. 